\title{
Comparison of spirometry data and symptoms between male and female smokers with chronic obstructive pulmonary disease
}

\author{
Rida Ajmal Khan ${ }^{\mathrm{a}}$, Hafiz Muhammad Waseem ${ }^{\mathrm{b}}$, Sadia Nazir ${ }^{\mathrm{c}}$, Shumaila Dogar ${ }^{\mathrm{d}}$, Mohsin Ali Cheema ${ }^{\mathrm{e}}$, \\ Khalid Parvez Lone ${ }^{f}$ \\ ${ }^{a}$ Assistant Professor, Department of Physiology, AUMDC, Green International University Lahore. \\ ${ }^{\mathrm{b}}$ Assistant Professor, Department of Physiology, Services Institute of Medical Sciences Lahore. \\ 'Associate Professor Department of Physiology, Lahore Medical \& Dental College Lahore. \\ ${ }^{\mathrm{d} A s s i s t a n t}$ Professor Department of Physiology, FMH College of Medicine \& Dentistry Lahore. \\ ${ }^{\mathrm{e} A s s o c i a t e}$ Professor Department of Physiology, AUMDC, Green International University Lahore. \\ fProfessor Department of Physiology, University of Health Sciences Lahore. \\ *Corresponding Author's e-mail: dr.ridakhan67@gmail.com
}

\begin{abstract}
BACKGROUND \& OBJECTIVE: Chronic Obstructive Pulmonary Disease (COPD) is a heterogeneous disease, showing the exaggerated response of airways to any injurious stimulus. It is no longer considered as the disease of men as it is becoming increasingly prevalent in females. Evidence suggests that gender affects the clinical presentation of the disease. The objectives of the study is to compare spirometry data between male and female smokers with COPD and to study the association of cough, sputum, and dyspnea with gender in smokers with COPD.

METHODOLOGY: This descriptive study was conducted at the University of Health Sciences Lahore. The study sample included 41 COPD patients with a history of smoking. After taking written informed consent, patients were recruited from the outpatient departments of tertiary care hospitals of Lahore by convenience sampling technique. A complete history was taken, and spirometry was done on each subject. The subjects were divided into male and female groups, followed by the comparison of Spirometry data between the groups and association of symptoms with gender using appropriate statistical techniques.

RESULTS: The results of this study demonstrated females were significantly younger and exhibited a greater decline of lung functions with similar pack-years history compared to male smokers with COPD. The most common presentation of females was breathlessness compared to male patients, who had sputum production as the most common presentation. CONCLUSION: Significant differences were seen in spirometry and clinical presentation of the disease in male and female COPD groups, showing the onset and symptomology of the disease.
\end{abstract}

ABSTRACT

KEYWORDS: COPD, Smokers, Spirometry.

\section{INTRODUCTION}

Chronic Obstructive Pulmonary Disease (COPD) shows post-bronchodilator irreversible airflow limitation ${ }^{[1]}$. It is a heterogeneous disease showing variation in terms of clinical and radiological presentation in patients with similar airflow limitations ${ }^{[2]}$. COPD is considered one of the leading causes of mortality worldwide, with increasing prevalence and mortality in the female population. This shift in the gender distribution of the disease is due to increasing trends of cigarette smoking in females along with other risk factors such as biomass exposure and socioeconomic status ${ }^{[3,4]}$. Females smokers show greater deterioration of lung functions, severe and early onset of COPD as compared to the male smokers with similar smoking history ${ }^{[5,6]}$. Moreover, evidence also suggests sex dimorphism and a difference in the clinical presentation of disease in male and female COPD patients, which canalso influencetheresponse to treatment ${ }^{[7,8]}$. The objectives of this study are to compare the spirometry data between male and female smokers with COPD and to study the association of cough, sputum and dyspnea with gender in smokers with COPD.

Khan RA, Waseem HM, Nazir S, Dogar S, Cheema MA, Lone KP. Comparison of spirometry data and symptoms between male and female smokers with chronic obstructive pulmonary disease. Journal of University Medical \& Dental College. 2021;12(4):244-247. 


\section{METHODOLOGY}

This comparative study was conducted and approved by the ethical committee of the University of Health Sciences Lahore in 2015. A sample size of 41 subjects was calculated and the subjects were recruited by convenience sampling from the outpatient department of tertiary care hospitals of Lahore. The subjects were divided into two groups, group A: Female $\mathrm{COPD}=18$ subjects and group $\mathrm{B}$ : Male $\mathrm{COPD}=23$ subjects. A complete history of the patients, including age, sex, socioeconomic status and medical history, was taken. All the study subjects were thoroughly assessed for their chief presenting complaints i.e., cough, sputum production and dyspnea and observations were recorded on the specifically predesigned performa for evaluation of these symptoms taken and recorded in the performa. All the subjects were middle to old age (40-80years), stable COPD patients diagnosed according to the GOLD criteria $(\mathrm{FEV} 1 / \mathrm{FVC}<70 \%)^{[9]}$. The subjects had similar ethnicity, i.e., Punjabi, Pakistani. Subjects diagnosed with asthma, tuberculosis, or exacerbation in the previous four weeks were excluded from the study. Spirometry on the subjects was performed using an electric spirometer (Spirolab 2, SDI Diagnostics, Inc., Bristol, MA 02375, USA), after ten minutes of giving the bronchodilator $(200 \mu \mathrm{g}$ salbutamol). For cigarette smokers, pack-years were calculated using the following formula:

Pack years $=($ No of cigarette smoking per day/20) $x$ No of smoking years.

For subjects with a history of huqqa smoking, pack-years were calculated by the same formula except that first the number of hours of smoking per day was converted to the number of cigarette smoking per day i.e., 20 min session of huqqa smoking was equal to 25 cigarettes and 45 mins huqqa session was equal to 60 cigarettes $^{[10]}$.

STATISTICAL ANALYSIS:

The complete data of this study was entered and analyzed by using IBM-SPSS version 20. The normality of quantitative data was assessed by the Shapiro-Wilk test. Mann-Whitney-U Test / students t- test was used for the comparison of demographic data (age, weight, height), pulmonary function tests, and pack-years between male and female groups. Qualitative variables like cough, sputum, and dyspnea were calculated in percentages and frequencies. A Chi-square test was applied to study the association of qualitative data with gender.

\section{RESULTS}

The female smokers with COPD were younger and showed greater deterioration of lung functions (FEV1, FVC, PEF, PEF50 \& PEF25) as compared to male smokers with COPD (p-value $<0.05$ ). Comparison of qualitative data e.g., cough, sputum production and dyspnea, were also done between the two groups. The data showed that the complain of dyspnea was more common in females $(p$-value $=0.00)$, while sputum production was more common in the male smokers having COPD ( $\mathrm{p}$-value $=0.04)$.

\section{DISCUSSION}

With the growing burden of COPD among the female population, it is very important to understand the gender related differences on spirometry and the clinical presentation of the disease. This study documents these differences in our local population. The results showed that females were younger compared to the male COPD group. The majority of the female recruited in the study were Huqqa smokers, and by conversion of huqqa smoking to pack-years, the parameter of pack-years became non-normally distributed in the female group. No significant difference of Median IQR of pack-years was seen between male and female groups. This showed that the two groups were similar on the basis of smoking status, emphasizing that gender may be an important parameter in COPD assessment and treatment. Regarding BMI, there was no significant difference in the male and female COPD groups. On spirometry, females presented more decline of lung functions compared to the male COPD group. The values of FEV1, FVC, PEF, PEF50 and PEF25 were significantly less in the female COPD group, whereas no significant difference was seen in the values of PEF75 and FEV1/FVC ratio. While comparing the qualitative data, results showed that females presented more with the complaint of breathlessness (dyspnea) compared to the male COPD group $\left(p=0.00^{*}\right)$, whereas male COPD patients presented more with the complaint of sputum production $(p=0.04 *)$. Similar results were shown by Varela et al., in a PLATINO study on Spanish population with a sample size of 5314 subjects ${ }^{[11]}$. The females in COPD and non-COPD groups showed more dyspnea and physical limitations compared to male groups (non-COPD: $54 \%$ versus 35\%, COPD: $63 \%$ versus 44\%). The reason for these differences was not very well understood, but it was suggested that it might be associated with hormonal effects on airways, or smaller size of female airways compared to males. In another study conducted on Spanish population by Ancochea et al., also concluded that females were younger, smoked less and on spirometry exhibited more decline of lung functions.

Regarding the respiratory symptoms, fewer women reported the symptoms of cough, sputum and wheeze and more reported the symptoms of dyspnea $(p<0.05)^{[12]}$. Watson et al in their study conducted on 3265 subjects, also presented similar results, concluding that female subjects were younger, with less pack year history compared to all male subjects ${ }^{[13]}$. The female patients with COPD came more with the complaint of severe dyspnea ( $29 \%$ women and $24 \%$ male, $\mathrm{p}<0.05$ ), but unlike our study there was no significant difference was seen in the presentation of other symptoms like cough and sputum production among the male and female COPD patients. However, a study conducted in China by Lu.M et al. showed different results. They confirmed that male gender, current smoking history or exposure to biomass fuel and residence in rural areas are the risk factors of severe dyspnea and chronic bronchitis ${ }^{[14]}$. A number of studies have tried to explain this difference in expression among male and female COPD patients. Mund et al., in their study, showed that with age, the BAL fluid taken 


\section{Khan RA, Waseem HM, Nazir S,}

from the lower airways of the females showed variation in the composition of the lymphocyte subgroups ${ }^{[15]}$. This property was not seen in the males. So, it was proposed that this change might be the cause of hyper responsive airways of the women, causing greater susceptibility and deterioration of the lungs to the cigarette smoke exposure. Blecklake et al. in their study documented biological sociocultural and environmental factors affecting the presentation of COPD in male and female patients ${ }^{[16]}$. They reported that sociocultural factors play an important role regarding the gender related difference in perception and reporting of COPD symptoms. For female COPD patients, shortness of breath was more culturally acceptable than the males, similarly for male COPD patients, sputum production and sleep disordered breathing was more socially and culturally acceptable.

Table-I: Comparison of demographic and spirometry parameters between Group-A (Female smokers with COPD) and Group-B (Male smokers with COPD).

\begin{tabular}{|c|c|c|c|c|}
\hline \multicolumn{2}{|c|}{ Parameters } & \multirow{2}{*}{$\begin{array}{c}\text { Group-A } \mathbf{N}=\mathbf{1 8} \\
53.88 \pm 10.8\end{array}$} & \multirow{2}{*}{$\begin{array}{c}\text { Group-B N= 23 } \\
63.34 \pm 11.76\end{array}$} & \multirow[t]{2}{*}{ p-value } \\
\hline Age (years) & Mean \pm SD & & & \\
\hline & Median (IQR) & $53.00(45.00-60.75)$ & $65.00(55.00-72.00)$ & $0.01^{\mathrm{a} *}$ \\
\hline \multirow[t]{2}{*}{ Weight (Kg) } & Mean $\pm \mathrm{SD}$ & $56.05 \pm 11.64$ & $61.39 \pm 9.82$ & \multirow[b]{2}{*}{$0.26^{b}$} \\
\hline & Median IQR & $62.50(44.50-65.00)$ & $60.00(54.00-66.00)$ & \\
\hline \multirow[t]{2}{*}{ Height (cm) } & Mean \pm SD & $157.44 \pm 5.14$ & $168.30 \pm 7.41$ & \multirow{2}{*}{$0.00^{\mathrm{a} *}$} \\
\hline & Median IQR & $157.00(153-162)$ & $169.00(165-174)$ & \\
\hline \multirow[t]{2}{*}{ BMI (Kg/m2) } & Mean \pm SD & $22.67 \pm 5.00$ & $21.63 \pm 2.92$ & \multirow[b]{2}{*}{$0.71^{b}$} \\
\hline & Median IQR & $24.01(17.13-26.29)$ & $20.42(20.04-23.38)$ & \\
\hline \multirow[t]{2}{*}{ Smoking in pack years } & Mean \pm SD & $145.62 \pm 226.04$ & $60.33 \pm 103.79$ & \multirow[t]{2}{*}{$0.63^{\mathrm{b}}$} \\
\hline & Median IQR & $42.5(11.87-187.50)$ & $34.00(19.50-62.50)$ & \\
\hline \multirow[t]{2}{*}{ FEV1 (Liters) } & Mean \pm SD & $0.94 \pm 0.28$ & $1.59 \pm 0.49$ & \multirow[t]{2}{*}{$0.00^{\mathrm{a} *}$} \\
\hline & Median IQR & $0.93(0.77-1.14)$ & $1.63(1.21-1.93)$ & \\
\hline \multirow[t]{2}{*}{ FVC (Liters) } & Mean \pm SD & $1.65 \pm 0.52$ & $2.66 \pm 0.66$ & \multirow{2}{*}{$0.00^{\mathrm{a} *}$} \\
\hline & Median IQR & $1.70(1.22-2.07)$ & $2.70(2.05-3.21)$ & \\
\hline \multirow[t]{2}{*}{ FEV1/FVC Ratio } & Mean \pm SD & $57.54 \pm 8.94$ & $59.19 \pm 7.91$ & \multirow[b]{2}{*}{$0.53^{b}$} \\
\hline & Median IQR & $60.20(49.32-64.62)$ & $60.80(56.30-66.30)$ & \\
\hline \multirow[t]{2}{*}{ PEF (Liters) } & Mean \pm SD & $1.33 \pm 0.44$ & $2.90 \pm 1.24$ & \multirow[b]{2}{*}{$0.00^{\mathrm{a} *}$} \\
\hline & Median IQR & $1.38(1.06-1.59)$ & $2.63(2.01-3.71)$ & \\
\hline \multirow[t]{2}{*}{ PEF75 (Liters) } & Mean \pm SD & $0.43 \pm 0.16$ & $0.45 \pm 0.18$ & \multirow{2}{*}{$0.74^{\mathrm{a}}$} \\
\hline & Median IQR & $0.39(0.30-0.59)$ & $0.40(0.30-0.60)$ & \\
\hline \multirow[t]{2}{*}{ PEF50 (Liters) } & Mean \pm SD & $0.74 \pm 0.30$ & $1.15 \pm 0.41$ & \multirow{2}{*}{$0.01^{\mathrm{a} *}$} \\
\hline & Median IQR & $0.69(0.51-0.92)$ & $1.26(0.75-1.43)$ & \\
\hline \multirow[t]{2}{*}{ PEF25 (Liters) } & Mean \pm SD & $1.01 \pm 0.39$ & $2.06 \pm 0.91$ & \multirow{2}{*}{$0.00^{\mathrm{a} *}$} \\
\hline & Median IQR & $0.99(0.79-1.25)$ & $2.16(1.35-2.38)$ & \\
\hline
\end{tabular}

${ }^{*}$ p-value $\leq 0.05$ is considered statistically significant ${ }^{b}$ p-value is generated by Mann-Whitney $U$ Test

\section{CONCLUSION}

This study shows that with similar exposure of cigarette/ huqqa smoke females show greater deterioration of lung functions. Our study has also highlighted the difference in the manifestation of the disease in male and female smokers with COPD. Relative to male patients, females presented more with breathlessness and males presented more with the complaint of sputum production. Our results verify that gender has a very important role in the heterogenic nature and presentation of COPD.

\section{LIMITATIONS \& FUTURE RECOMMENDATIONS:}

The study has some limitations:

1. The sample size of 41 subjects is not large enough to substantiate the results for whole Pakistani population.

2. There is a dearth of female patients diagnosed with COPD and with predominant smoking history.
${ }^{a}$ p-value is generated by Independent Sample t-Test

Further studies with a much larger sample size are required to completely comprehend the role of gender in the heterogenicity of this disease in our population.

Table-II: Association of gender with presenting complain of smokers having COPD. Values are given in frequencies and percentages.

\begin{tabular}{|c|c|c|c|c|}
\hline \multicolumn{2}{|c|}{ Variables } & \multirow{2}{*}{$\begin{array}{c}\begin{array}{c}\text { Group-A Female } \\
\text { COPD }(\mathbf{n}=\mathbf{1 8})\end{array} \\
12(66.7 \%)\end{array}$} & \multirow{2}{*}{$\begin{array}{c}\begin{array}{c}\text { Group-B Male } \\
\text { COPD }(\mathbf{n}=\mathbf{2 3})\end{array} \\
15(65.2 \%)\end{array}$} & \multirow{2}{*}{ p-value } \\
\hline Cough & Yes & & & \\
\hline & No & $6(33.3 \%)$ & $8(38.8 \%)$ & 0.92 \\
\hline \multirow[t]{2}{*}{ Spectum } & Yes & $6(33.3 \%)$ & $15(65.2 \%)$ & $0.04 *$ \\
\hline & No & $12(66.7 \%)$ & $8(34.8 \%)$ & \\
\hline \multirow[t]{2}{*}{ Dyspnea } & Yes & $18(100 \%)$ & $8(34.8 \%)$ & $0.00^{*}$ \\
\hline & No & - & $15(65.2 \%)$ & \\
\hline
\end{tabular}

$* \mathrm{p}<0.05$ was considered statistically significant. 
ACKNOWLEDGEMENT: None.

CONFLICT OF INTEREST: None.

GRANT SUPPORT AND FINANCIAL DISCLOSURE:

University of Health Sciences Lahore.

DISCLAIMER: This manuscript is part of the M.Phil. thesis of Dr. Rida Ajmal Khan, under the supervision of Prof. Dr. Khalid. P. Lone.

\section{REFERENCES:}

1. Pascoe SJ, Wu W, Collison KA, Nelsen LM, Wurst $\mathrm{KE}$, Lee LA. Use of clinical characteristics to predict spirometric classification of obstructive lung disease. International Journal of Chronic Obstructructive Pulmonary Disease. 2018; 13:889-902. Doi: 10.2147/ COPD.S153426

2. Choi JY, Kim SY, Lee JH, Park YB, Kim YH, Um S-J, et al. Clinical Characteristics of Chronic Obstructive Pulmonary Disease in Female Patients: Findings from a KOCOSS Cohort. International Journal of Chronic Obstructive Pulmonary Disease. 2020; 15:2217-2224. Doi: 10.2147/COPD.S269579

3. Trigueros JA, Riesco JA, Alcázar-Navarrete B, Campuzano A, Pérez J. Clinical Features Of Women With COPD: Sex Differences In A Cross-Sectional Study In Spain ("The ESPIRAL-ES Study"). International Journal of Chronic Obstructructive Pulmonary Disease 2019; 14:2469-2478. Doi: 10.2147/COPD.S217921

4. Ntritsos G, Franek J, Belbasis L, Christou MA, Markozannes G, Altman P, et al. Gender-specific estimates of COPD prevalence: a systematic review and meta-analysis. International Journal of Chronic Obstructructive Pulmonary Disease. 2018;13:15071514. Doi: 10.2147/COPD.S146390

5. Gut-Gobert C, Cavaillès A, Dixmier A, Guillot S, Jouneau S, Leroyer C, et al. Women and COPD: do we need more evidence? European Respiratory Review. [Internet] 2019 [cited 2021 Apr 19];28(151). Available from: https://err.ersjournals.com/ content/28/151/180055. Doi:10.1183/16000617.00552018

6. Barnes PJ. Sex Differences in Chronic Obstructive Pulmonary Disease Mechanisms. American Journal of Respiratory and Critical Care Medicine [Internet] 2016 [cited 2021 Jul 7]; Available from: https://www. atsjournals.org/doi/10.1164/rccm.201512-2379ED

7. Matera MG, Ora J, Calzetta L, Rogliani P, Cazzola M. Sex differences in COPD management. Expert Review of Clinical Pharmacology. 2021;14(3):323-332. Doi: 10.1080/17512433.2021.1888713

8. Hardin M, Cho MH, Sharma S, Glass K, Castaldi PJ, McDonald M-L, et al. Sex-Based Genetic Association Study Identifies CELSR1 as a Possible Chronic Obstructive Pulmonary Disease Risk Locus among Women. American Journal of Respiratory and Cell Molecular Biology. 2017;56(3):332-341. Doi: 10.1165/ rcmb.2016-0172OC
9. Mirza S, Clay RD, Koslow MA, Scanlon PD. COPD Guidelines: A Review of the 2018 GOLD Report. Mayo Clinic Proceedings. 2018;93(10):1488-1502. Doi: 10.1016/j.mayocp.2018.05.026

10. Masters N, Tutt C, Yaseen N. Waterpipe tobacco smoking and cigarette equivalence. British Journal of General Practice: The Journal of Royal College of General Practitioners. 2012;62(596):127. Doi:10.3399/ bjgp12X631231

11. Varela MVL, Oca MM de, Halbert RJ, Muiño A, PerezPadilla R, Tálamo C, et al. Sex-related differences in COPD in five Latin American cities: the PLATINO study. European Respiratory Journal. 2010;36(5):10341041. Doi: 10.1183/09031936.00165409

12. Ancochea J, Miravitlles M, García-Río F, Muñoz L, Sánchez G, Sobradillo V, et al. Underdiagnosis of chronic obstructive pulmonary disease in women: quantification of the problem, determinants and proposed actions. Archivos De Bronconeumologia. 2013;49(6):223-229. Doi: 10.1016/j.arbres.2012.11.010

13. Watson L, Vestbo J, Postma DS, Decramer M, Rennard $\mathrm{S}$, Kiri VA, et al. Gender differences in the management and experience of Chronic Obstructive Pulmonary Disease. Respiratory Medicine. 2004;98(12):12071213. Doi: 10.1016/j.rmed.2004.05.004

14. Lu M, Yao W, Zhong N, Zhou Y, Wang C, Chen P, et al. Chronic obstructive pulmonary disease in the absence of chronic bronchitis in China. Respirology Carlton Vic. 2010;15(7):1072-1078. Doi: 10.1111/j.14401843.2010.01817.x.

15. Mund E, Christensson B, Larsson K, Grönneberg R. Sex dependent differences in physiological ageing in the immune system of lower airways in healthy nonsmoking volunteers: study of lymphocyte subsets in bronchoalveolar lavage fluid and blood. Thorax 2001;56(6):450-455. Doi:10.1136/thorax.56.6.450

16. Becklake M, Kauffmann F. Gender differences in airway behaviour over the human life span. Thorax. 1999;54(12):1119-1138. Doi: 10.1136/thx.54.12.1119

\section{Authors Contribution:}

Rida Ajmal Khan: Made substantial contributions to the conception and design of the study and wrote the original draft of the manuscript.

Hafiz Muhammad Waseem: Data collection and contribution towards data analysis.

Sadia Nazir: Performed data analysis and revision of initial manuscript.

Shumaila Dogar: Designed the analysis and corrections.

Mohsin Ali Cheema: Conceived and designed the analysis. Proof reading of the manuscript.

Khalid Parvez Lone: Overall supervisor of the project.

\section{Submitted for Publication:03-03-2021 Accepted after revision: 05-07-2021}

